Effects of anode temperature on the arc volt-ampere characteristics and ejected plume property of a low-power supersonic plasma

This article has been downloaded from IOPscience. Please scroll down to see the full text article.

2011 Plasma Sources Sci. Technol. 20065006

(http://iopscience.iop.org/0963-0252/20/6/065006)

View the table of contents for this issue, or go to the journal homepage for more

Download details:

IP Address: 159.226.231.78

The article was downloaded on 20/03/2012 at 09:19

Please note that terms and conditions apply. 


\title{
Effects of anode temperature on the arc volt-ampere characteristics and ejected plume property of a low-power supersonic plasma
}

\author{
W X Pan, X Meng, H J Huang and C K Wu \\ Institute of Mechanics, Chinese Academy of Sciences, Beijing 100190, People's Republic of China \\ E-mail: huang@imech.ac.cn
}

Received 2 August 2010, in final form 8 February 2011

Published 22 November 2011

Online at stacks.iop.org/PSST/20/065006

\begin{abstract}
Low-power plasma generators with two kinds of hot anode/nozzle structures, one with a natural radiation-cooled nozzle and the other with a regeneratively cooled nozzle, were designed to investigate the dependence of the volt-ampere characteristics on the anode temperature. Pure argon, nitrogen or hydrogen gas was used as the plasma working gas at input powers from 130 to $1200 \mathrm{~W}$ in a plenum chamber kept at a pressure of below $20 \mathrm{~Pa}$. Variations of the arc voltage with changes in arc current, gas flow rate and firing time (anode temperature) were examined, and the effects of the arc volt-ampere characteristics on the properties of the ejected plasma flow from the nozzle exit are discussed with respect to the evaluation of the average plume temperature and flow velocity. Results show that there are definitely non-negligible effects of anode temperature on these characteristics.
\end{abstract}

(Some figures may appear in colour only in the online journal)

\section{Introduction}

Non-transferred direct current (dc) arc plasmas are widely used for spray coating of hard or heat-resistant materials on metal surfaces $[1,2]$, surface cladding or re-melting hardening [3,4], nanoparticle syntheses or film depositions [5-7], and for testing the thermal properties of materials [8]. In these processes, torches for generating the thermal plasma normally have a water-cooled anode kept at almost a constant bulk temperature, which is not much higher than room temperature, during the whole procedure. Thus, every torch has its inherent volt-ampere characteristics according to its structure, and the flow rate and type of working gas, and users do not observe any change in the arc volt-ampere characteristics under a given set of working conditions before heavy erosion on the electrode surface occurs to cause any structural damage.

However, there are other kinds of non-transferred dc arc plasma torches with radiation- or gas-cooled but not water-cooled anodes [7,9-17]. The anode temperature rises continuously with the increase in working time at the beginning stage of firing at a certain rate, and will stabilize at a final temperature dependent on the anode structure, cooling method, input power level, gas type and feeding rate. Some hot anode torches are designed for industrial use, working at a relatively high power level [9], some of them are used for hard material deposition of nanostructures $[10,11]$, and a large number of hot anode/nozzle torches, called arc-heated jet (arcjet) thrusters at input powers of around several kilowatts, are used in space propulsion, mainly for the north-south station-keeping of communication satellites [12-17]. The plasma plume from hot anode torches used for nano-material deposition and arcjet thrusters is in supersonic flow. Many research papers have reported the volt-ampere characteristics of arcjet thrusters $[14,18,19]$ and several reports have dealt with their arc root attachment on the anode surface [20,21]; these are done after a period of firing when the anode is heated to an extent close to its final stable condition. It was found that the position and manner of the arc root attachment on the anode surface changed appreciably with increasing anode temperature after ignition, even though the arc current and the gas-feeding rate were kept constant [22]. This suggests that the arc voltage could hardly be kept at a constant value during the period of rising anode 


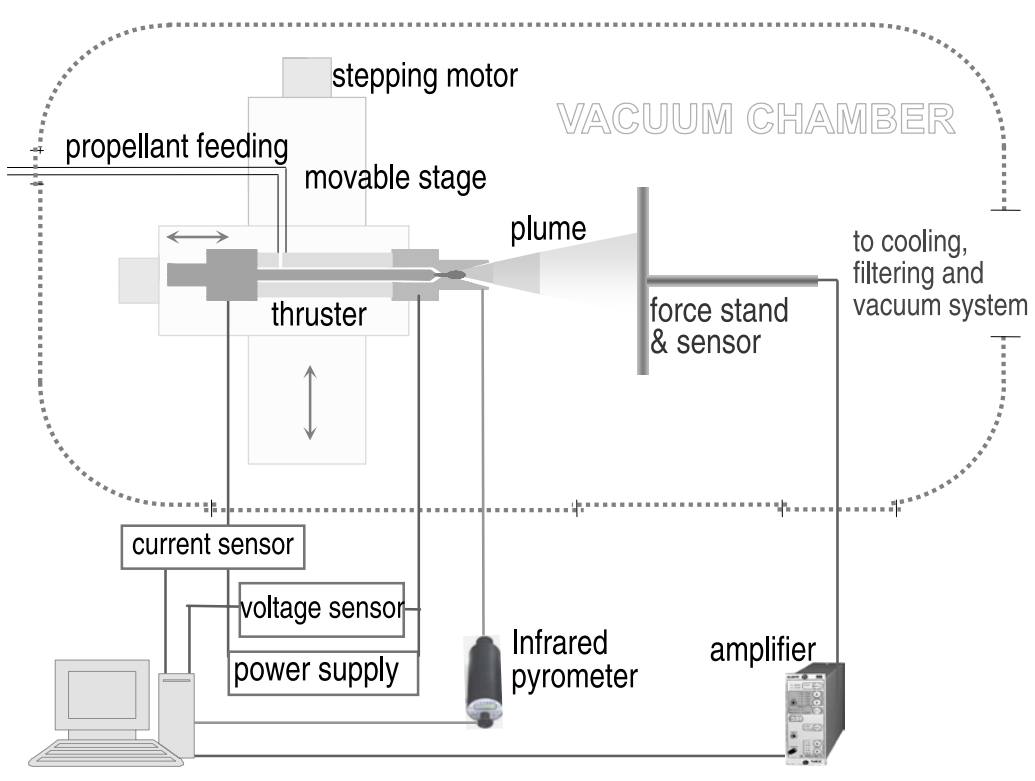

Figure 1. Schematic drawing of the experimental system and setup.

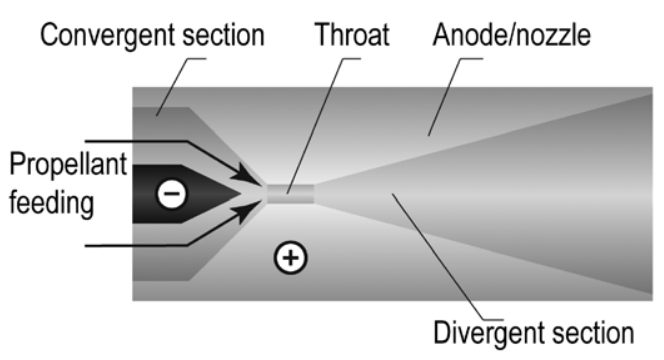

(a)

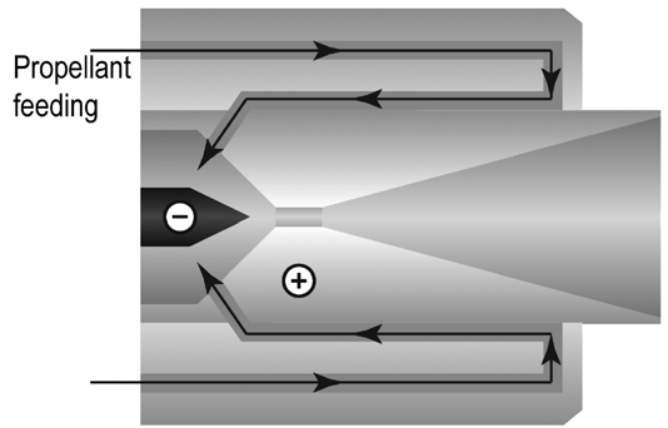

(b)

Figure 2. Schematic diagrams of the two different anode/nozzles: $(a)$ radiation-cooled and $(b)$ regeneratively cooled.

temperature. The input power will change if the arc voltage changes, and hence the plume parameter might also be affected. However, few reports can be found which discuss the effect of anode temperature on the volt-ampere characteristics and ejected plume property of low-power supersonic plasmas [23]. These effects could possibly affect the process performance, stability and controllability.

In this work, pure argon, nitrogen or hydrogen gas is used as the plasma working gas. Torches with two kinds of anode/nozzle structures are investigated, one with a natural radiation-cooled nozzle and the other with a regeneratively cooled nozzle. The dependence of the voltampere characteristics on the anode temperature and gas flow rate is examined, and the effects on the properties of the ejected plasma flow are discussed with respect to the estimated average plume temperature and velocity.

\section{Experimental conditions}

The plasma generator was set in a vacuum chamber of $2 \mathrm{~m}$ diameter and $4 \mathrm{~m}$ length as shown in figure 1 , with pure argon, nitrogen or hydrogen as the working gas at input powers from 130 to $1200 \mathrm{~W}$. The pumping system is capable of keeping the chamber pressure below $10 \mathrm{~Pa}$ with a gas flow rate of $5 \mathrm{slm}$, about $148 \mathrm{mg} \mathrm{s}^{-1}$ for argon. Two generators, as shown in figure 2, with the different anode/nozzle cooling methods were used by passing cold gas through the outer surface of the hot nozzle before entering the convergent section and being archeated. The two generators had the same inner structure of anode/nozzle with a throat $0.7 \mathrm{~mm}$ in diameter, $2.3 \mathrm{~mm}$ long, and a divergent half angle of $15^{\circ}$. The nozzle material was tungsten with $\sim 2 \%$ cerium oxide. The generator was fixed on a movable stage driven accurately along the plume axial and radial directions by stepping motors. A heat-resistant metal plate of diameter $200 \mathrm{~mm}$ was set perpendicular to the plume axis, and attached to a sensitive force transducer to receive the impact effect of the plume, which is equal to the thrust acting on the generator [24]. The temperature of the anode/nozzle outer wall was monitored simultaneously with two infrared pyrometers of working ranges $200-600^{\circ} \mathrm{C}$ (working wavelength $1.55 \mu \mathrm{m}$ ) and $600-2000^{\circ} \mathrm{C}$ (working wavelength $1.06 \mu \mathrm{m}$ ), while the emission coefficient of the nozzle surface was estimated to be around 0.31 . This value was chosen as a compromise between the handbook values and tungsten ribbon lamp calibrations, taking into consideration the real surface conditions of the nozzle and the relative nature of 


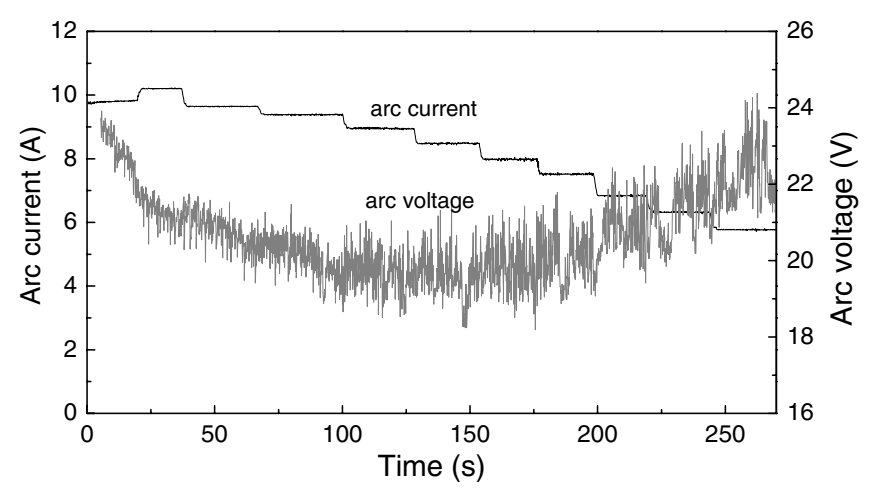

Figure 3. Time variation of arc current (manually set) and arc voltage in a generator with a radiation-cooled nozzle at an argon feeding rate of $62 \mathrm{mg} \mathrm{s}^{-1}$.

the measurement in this work. Signals from the force, arcvoltage and arc-current sensors were sampled depending on time by a data acquisition and processing system, as shown in figure 1. The use of transducers and a high-speed data acquisition system makes it possible to acquire the controllable parameters, arc current and mass flow rate, in quick steps and takes down the whole set of data in short time intervals. The continuous measuring and recording clearly show the rising or falling trends of the parameters. The specific impulse (which is numerically approximately equal to the average axial velocity at the nozzle exit) is $I_{\mathrm{sp}}=F / m$, where $F$ is the measured thrust and $m$ is the mass flow rate; the thrust efficiency (conversion efficiency from the input electric power for arc heating of the working gas to the gas kinetic energy) is $\eta=$ $\left(F^{2}-F_{\mathrm{c}}^{2}\right) / 2 m P$, where $P$ is the input electric power and $F_{\mathrm{c}}$ is the cold thrust when the gas is fed before firing; and the specific power is $P / m$.

\section{Results and discussion}

\subsection{Variation of arc voltage in a generator with a radiation-cooled nozzle}

In the first part of the study, a generator with a radiation-cooled nozzle was used, and a limited amount of data was collected. These initial data are shown here only to demonstrate that during the period of initial heating of the nozzle/anode, there are noticeable changes in the characteristics of the arc. Data of arc voltage with various values of the arc current were collected during the period of rising anode temperature. Figure 3 shows the arc current (manually set to different values) and the corresponding arc voltage measured at various times after ignition in the generator with the radiation-cooled anode/nozzle at a fixed argon feeding rate of $62 \mathrm{mg} \mathrm{s}^{-1}$. The arc voltage changed only by several volts with the change in arc current from 10.2 to $5.8 \mathrm{~A}$, but it definitely shows different trends in relation to the arc current as the anode is heated up. This can be more clearly seen in figure 4. The average arc voltage decreased with decreasing arc current at the beginning stage of firing until about $140 \mathrm{~s}$, and then increased with decreasing arc current at the later stage of firing. Each data point in figure 4 indicates the voltage value at the middle

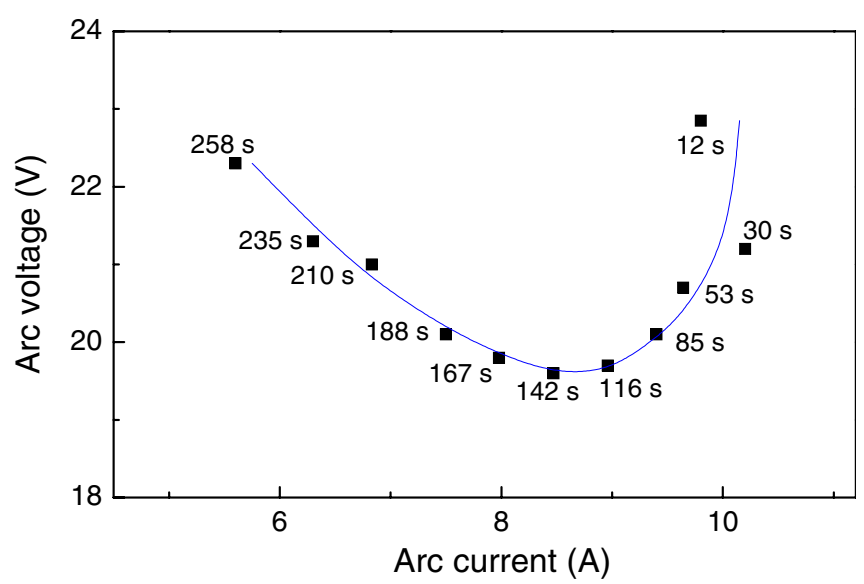

Figure 4. Volt-ampere readings taken at various times after firing in a generator with a radiation-cooled nozzle at an argon feeding rate of $62 \mathrm{mg} \mathrm{s}^{-1}$.

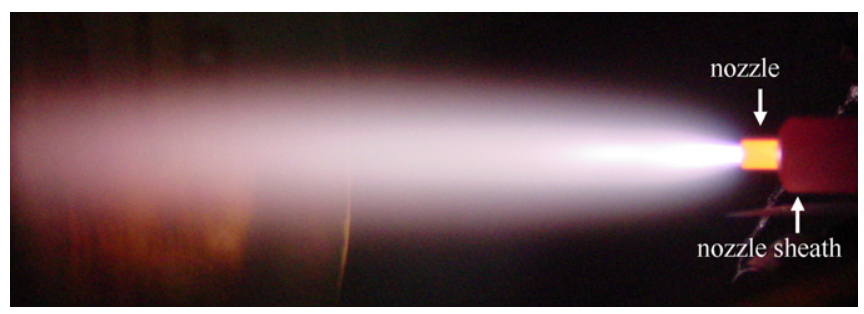

Figure 5. Emission situation of the plasma plume and radiation-cooled nozzle under steady-state conditions at an argon feeding rate of $62 \mathrm{mg} \mathrm{s}^{-1}$ and arc current of $10.2 \mathrm{~A}$.

time in the period at a fixed arc current. Since the plasma was ignited at room temperature and the anode/nozzle was radiation cooled, the nozzle temperature increased with the increase in firing time, due to heavy heating of the nozzle by the arc discharge and the very low radiation effect of the nozzle surface at low temperatures, at the beginning stage of firing. Figure 5 shows that, after a certain firing time, the nozzle was heated to a relatively high temperature and so was the nozzle sheath.

\subsection{Variation of arc voltage in a generator with a regeneratively cooled nozzle}

A regeneratively cooled nozzle, with the purpose of raising the energy efficiency of the generator, was later designed and tested more thoroughly. When the arc was ignited in this generator at $8 \mathrm{~A}$ and an argon flow rate of about $100 \mathrm{mg} \mathrm{s}^{-1}$, the arc voltage decreased from $29.2 \mathrm{~V}$ at $245 \mathrm{~s}$ to $27.4 \mathrm{~V}$ at $745 \mathrm{~s}$ of firing time, and further to $25.5 \mathrm{~V}$ at $2275 \mathrm{~s}$, as shown in figure 6.

Figure 7 shows the temperature variation of the outer surface of the nozzle with firing time, detected by the infrared pyrometer. Measurement data below $600 \mathrm{~K}$ were not used because of pyrometer sensitivity problems and interference signals from the plume emission of the plasma. The black solid line in figure 7 indicates the measured result after the firing time of about $100 \mathrm{~s}$ and when the nozzle temperature was above $600 \mathrm{~K}$. At the ignition time, the nozzle was at room 


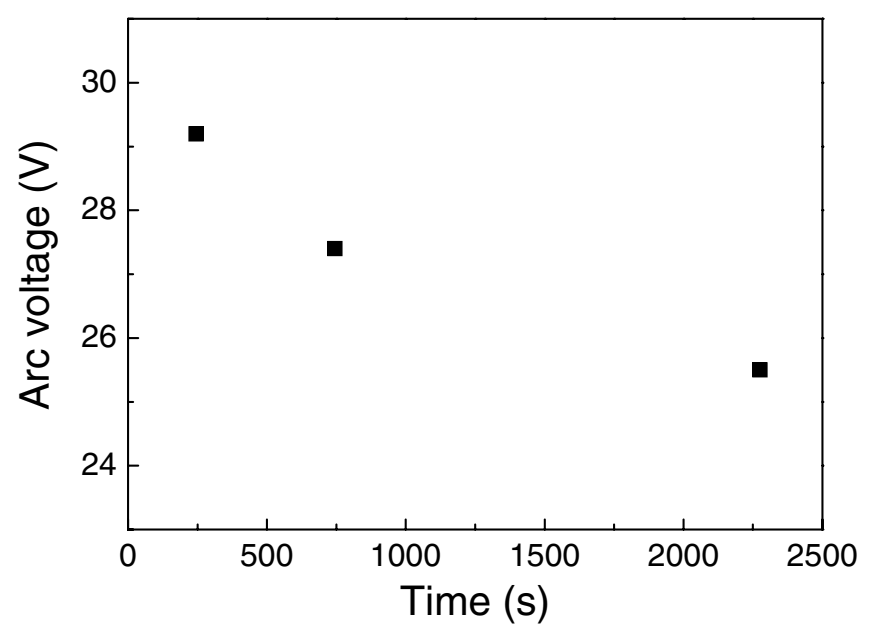

Figure 6. Variation of arc voltage with firing time at a fixed arc current of $8 \mathrm{~A}$ and argon flow rate of $100 \mathrm{mg} \mathrm{s}^{-1}$.

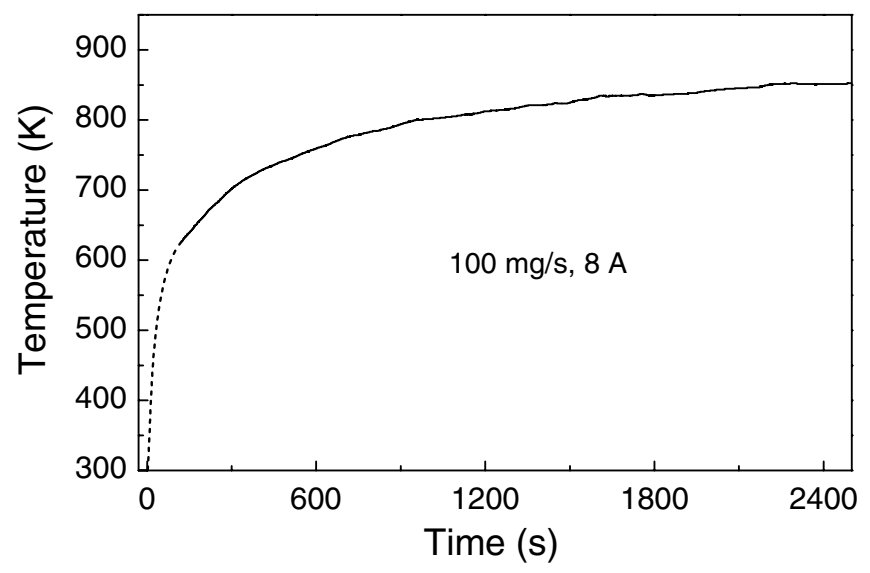

Figure 7. Variation of nozzle temperature with firing time at a fixed argon flow rate of $100 \mathrm{mg} \mathrm{s}^{-1}$ and arc current of $8 \mathrm{~A}$.

temperature, and the dashed line in the figure is the estimated nozzle temperature variation after ignition. It can be seen that the nozzle temperature rose relatively quickly until $900 \mathrm{~s}$ after ignition, then rose quite slowly, and finally stabilized at about $850 \mathrm{~K}$ after the firing time of around $2000 \mathrm{~s}$, at the argon feeding rate of $100 \mathrm{mg} \mathrm{s}^{-1}$ and arc current of $8 \mathrm{~A}$. Figure 8 indicates that the regeneratively cooled nozzle remained at a relatively low temperature even after a firing time over $2000 \mathrm{~s}$ at a high argon feeding rate of $270 \mathrm{mg} \mathrm{s}^{-1}$ and high arc current of $12 \mathrm{~A}$, and it appeared as dark red at a low flow rate of $100 \mathrm{mg} \mathrm{s}^{-1}$ and $12 \mathrm{~A}$.

\subsection{Variation of the volt-ampere characteristics with firing time (nozzle temperature)}

The slowly changing nozzle temperature and arc characteristics under relatively stable working conditions could provide enough time for process examination, thus only the results of the generator with regeneratively cooled nozzle will be shown and discussed here.

Since the nozzle temperature rose relatively slowly, and the measuring system was fast-acting, it was possible to take a number of data sets at various time periods after firing. This was done with the generator with the regeneratively cooled nozzle. Figure 9 shows the volt-ampere curves taken in different time periods with various argon flow rates as indicated in the figure. At the beginning stage of firing (60-360 s), the arc voltage rose with increasing arc current with a relatively high slope, then tended to change more slowly and further on turned to a decreasing slope with increasing arc current. The gas-feeding rate ranged from 86 to $139 \mathrm{mg} \mathrm{s}^{-1}$ for the cases in figure 9. But the flow rate does not seem to affect the slope of the $\mathrm{V}-\mathrm{A}$ curve during the same time period.

The slope of the volt-ampere characteristic curve of the lines in figure 9 are plotted against the firing time in figure 10, taking the middle of each duration in figure 9 as the time value. It can be seen that the trend of volt-ampere characteristic variation follows a clearly unified relationship, falling from a positive slope in the starting period towards a negative value in the later stage, and tends to stabilize after the firing time of about $1000 \mathrm{~s}$, regardless of the different gas-feeding rates.

Generally, a channel-restricted arc will show rising volt-ampere characteristics with the arc current, and a less constricted or free-burning arc will show falling characteristics. With the present nozzle/anode configuration, the anodic attachment position of the arc may change appreciably during the heating-up period of the nozzle. A previous study [22] has shown the change of arc spot in such a nozzle/anode from a constricted to a diffused one during the heating-up period. The position of the anodic arc root attachment should also change with the anode temperature [23]. A numerical simulation [25] predicts the arc root to be positioned near the downstream end of the throat in the present configuration under steady-state conditions. At the beginning stage of firing while the nozzle temperature is still relatively low, the attachment spot could be further constricted, and the throat could become a cold constrictive passage for the arc column. Accordingly, rising volt-ampere characteristics could appear, as commonly occur in constricted arcs. The restrictive effect of the nozzle throat on the arc column could diminish with the increase in firing time and nozzle temperature; the arc column could expand with increasing arc current, resulting in reduced current density and falling voltampere characteristics. The arc attachment position might also diffuse to a wider region, further reducing the constrictive effect of the throat channel, making the arc more like a freeburning one.

Since it is very difficult to make direct observations inside the nozzle throat, and numerical simulations that can accurately describe such complex phenomena are not yet available, these explanations can at best be speculative discussions, based upon general knowledge on electric arc generators.

The above results indicate that variations of arc voltage with arc current showed a similar pattern in either the regeneratively or radiation-cooled anode. That is, the arc voltage rises with the increase in arc current at the beginning stage of firing, and then turns to falling characteristic after the anode temperature rises to some elevated value. This transition 

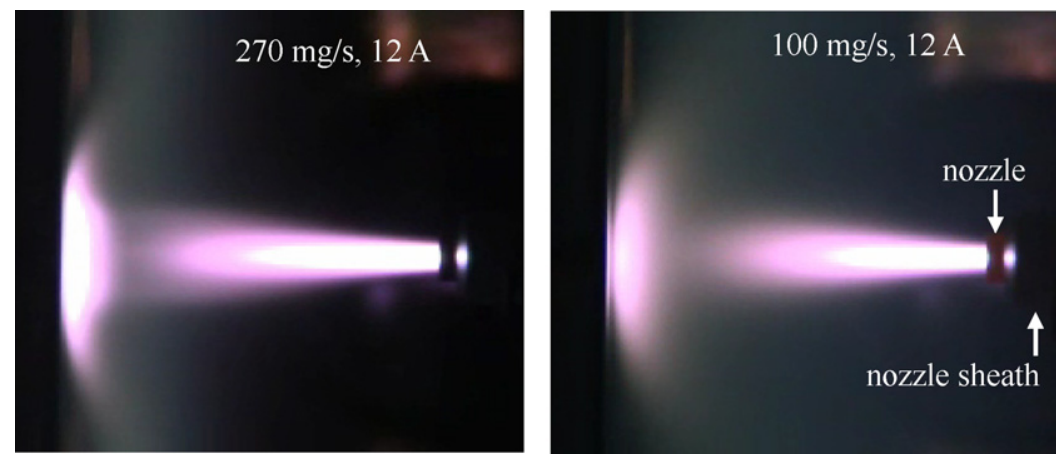

Figure 8. Emission situations of the plasma plume and regeneratively cooled nozzle at an arc current of $12 \mathrm{~A}$ and argon feeding rates of $270 \mathrm{mg} \mathrm{s}^{-1}$ (left) and $100 \mathrm{mg} \mathrm{s}^{-1}$ (right).

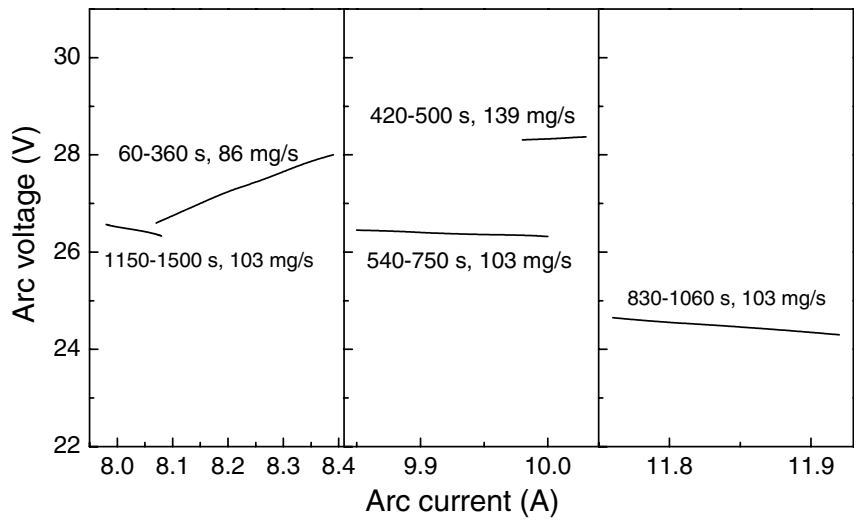

Figure 9. Volt-ampere curves in a generator with a regeneratively cooled nozzle at different argon feeding rates and time durations.

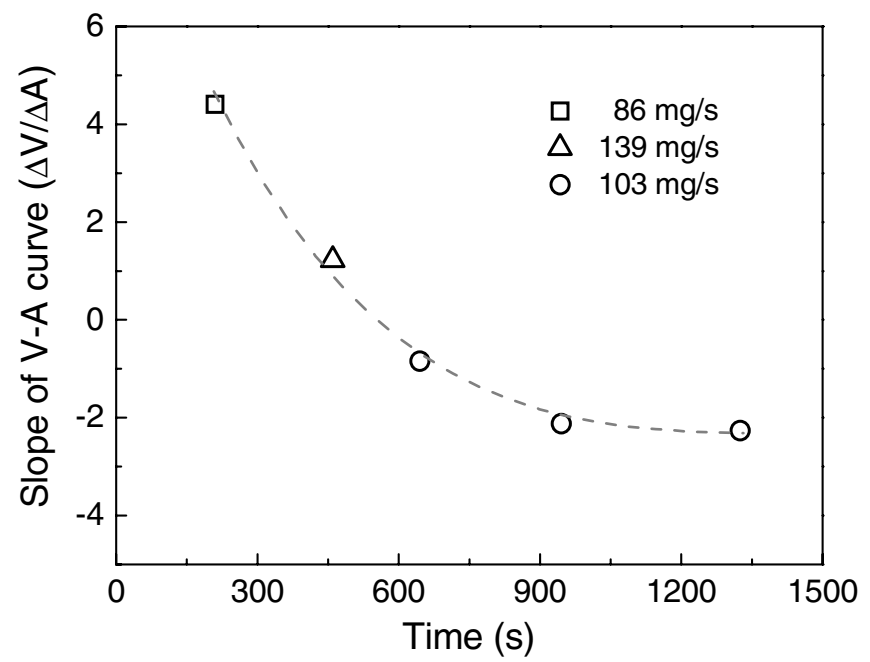

Figure 10. Time variation of the slope of the volt-ampere characteristic curve in figure 9 .

takes place much faster in the generator with the radiationcooled nozzle than that with the regeneratively cooled one, due to the fact that the former heats up much faster. The results in figure 10 also indicate that the change in gas flow rate apparently does not affect the rate of slope variation of the volt-ampere characteristic curve with the anode temperature (firing time).

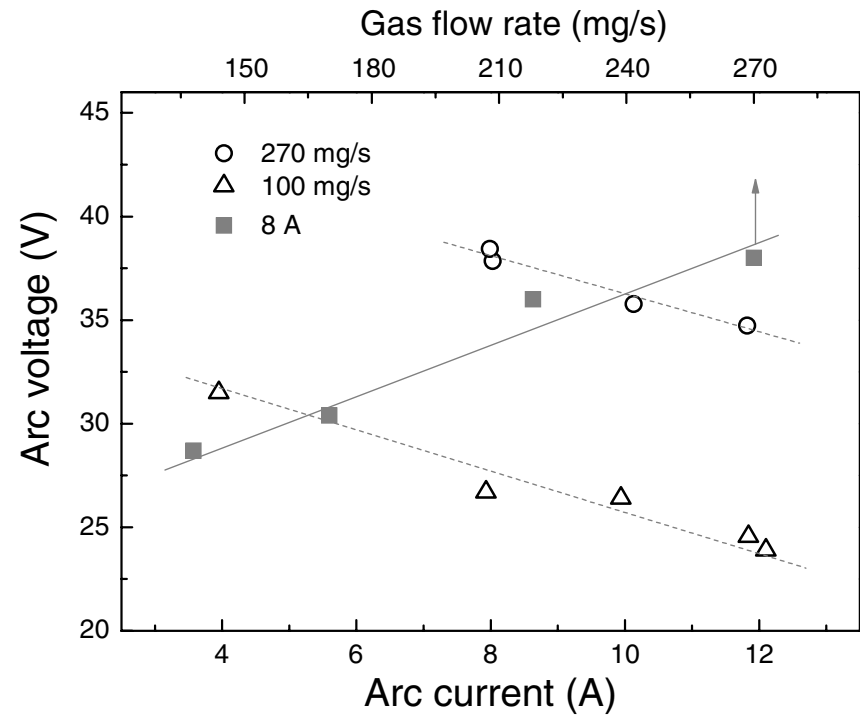

Figure 11. Variations of arc voltage with arc current and argon feeding rate in a generator with a regeneratively cooled nozzle after a firing time of $1000 \mathrm{~s}$.

\subsection{Volt-ampere characteristics of $\mathrm{Ar}, \mathrm{N}_{2}$ or $\mathrm{H}_{2}$ arc after a certain time of firing}

In the generator with the regeneratively cooled nozzle, voltampere curves took on their 'normal' characteristics after the firing time of about $1000 \mathrm{~s}$ for the argon arc, as shown in figure 10 , but about $130 \mathrm{~s}$ for nitrogen and $100 \mathrm{~s}$ for hydrogen arcs, due to the different heat transfer properties of each working gas. The stabilized nozzle temperature could be over $1300 \mathrm{~K}$ and $1700 \mathrm{~K}$ with nitrogen and hydrogen arc heating, respectively, which was much higher than that of $<900 \mathrm{~K}$ with argon arc heating.

Figure 11 shows the volt-ampere characteristics of the argon arc after $1000 \mathrm{~s}$ of firing. The arc voltage increased with increasing argon feeding rate and decreased with increasing arc current. Figures 12 and 13 show that the nitrogen and hydrogen arcs also have similar volt-ampere characteristics as the argon arc after a firing time of $130 \mathrm{~s}$. However, the variation of the hydrogen arc current affected its arc voltage only slightly, while its arc voltage increased appreciably with increasing mass flow rate. These different kinds of characteristics are difficult to explain because the arc behaviour 


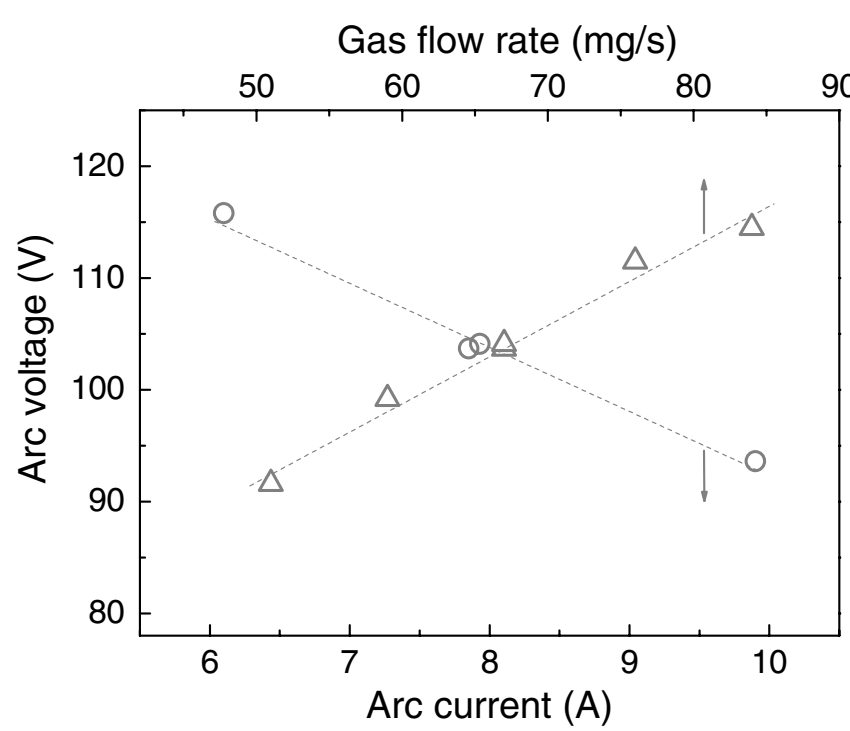

Figure 12. Variations of arc voltage with arc current at a fixed nitrogen flow rate of $67 \mathrm{mg} \mathrm{s}^{-1}$ and with nitrogen feeding rate at a fixed arc current of $8 \mathrm{~A}$ after a firing time of $130 \mathrm{~s}$.

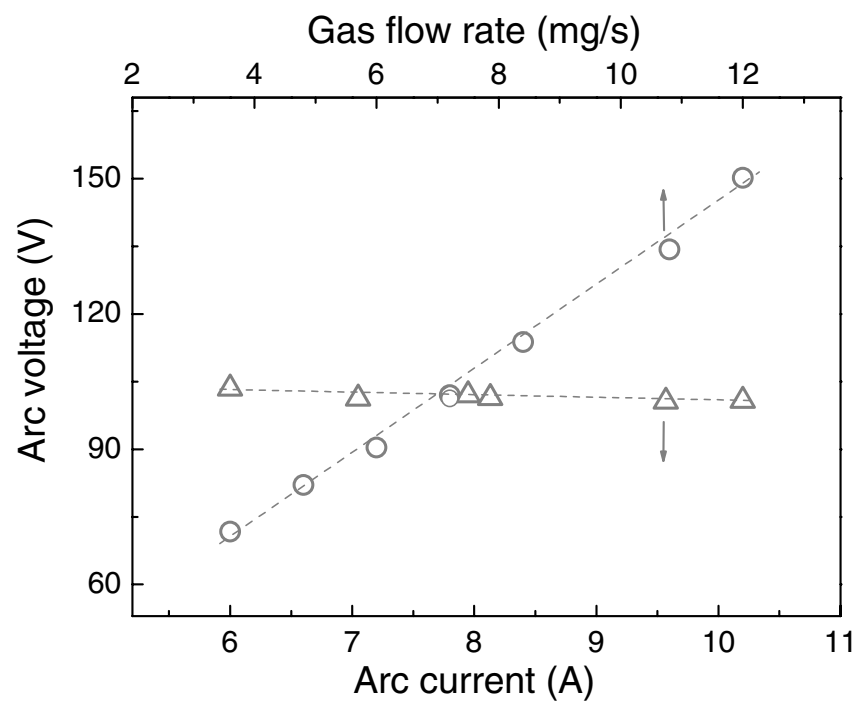

Figure 13. Variations of arc voltage with arc current at a fixed hydrogen flow rate of $7.2 \mathrm{mg} \mathrm{s}^{-1}$ and with hydrogen feeding rate at a fixed arc current of $8 \mathrm{~A}$ after a firing time of $130 \mathrm{~s}$.

in different gases might be quite different in this specific anode/nozzle structure for generating a supersonic plasma jet. The generator has a convergent section for compressing the working gas, a small diameter throat and a divergent section for gas expansion. The maximum volume flow rate of argon, nitrogen and hydrogen in figures $11-13$ was about $151 \mathrm{~cm}^{3} \mathrm{~s}^{-1}$, $67 \mathrm{~cm}^{3} \mathrm{~s}^{-1}$ and $135 \mathrm{~cm}^{3} \mathrm{~s}^{-1}$, respectively. But the highest pressures in the convergent section were over $0.5 \mathrm{MPa}$ and 0.4 MPa for the case of argon and nitrogen, respectively, and lower than 0.2 MPa for the case of hydrogen. At the fixed hydrogen flow rate of $7.2 \mathrm{mg} \mathrm{s}^{-1}$ in figure 13 , the change in arc current from 7 to 10.2 A caused only a slight pressure increase in the convergent section from 0.11 to $0.12 \mathrm{MPa}$, while an apparent pressure increase from 0.06 to $0.18 \mathrm{MPa}$ occurred on increasing the flow rate from 3.6 to $12 \mathrm{mg} \mathrm{s}^{-1}$ at a fixed arc

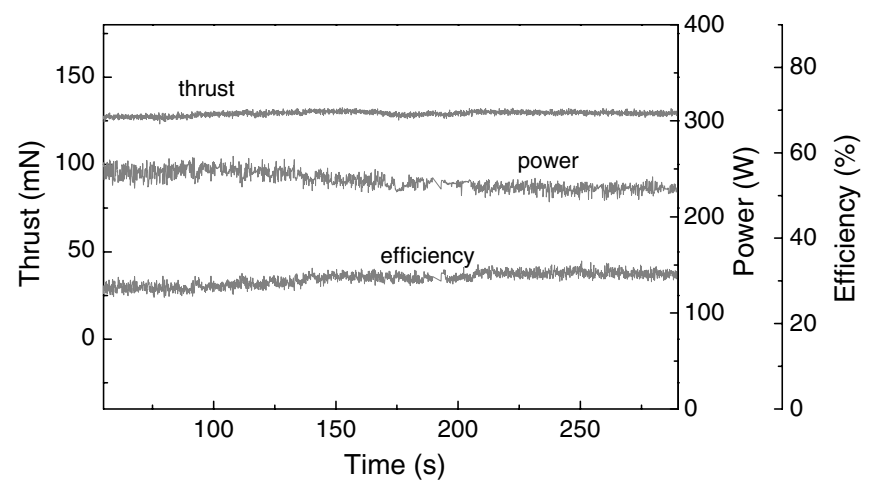

Figure 14. Variation of input power, thrust and thrust efficiency with firing time at an argon feeding rate of $100 \mathrm{mg} \mathrm{s}^{-1}$ and arc current of $8 \mathrm{~A}$.

current of $8 \mathrm{~A}$. These experimental results could be caused by the combined effects of different arc root attachment modes, different heat transfer, dissociation or ionization behaviours in the arc column, etc, in different gases, and their effects on the structure of the arc under various current values.

\subsection{Effects of arc behaviour on the properties of the plasma plume}

Figure 14 shows the variations of input power, nozzle temperature, thrust and thrust efficiency with firing time at a fixed argon feeding rate of $100 \mathrm{mg} \mathrm{s}^{-1}$ and arc current of $8 \mathrm{~A}$. According to the results in figures 9 and 10, the arc has a reducing slope of volt-ampere characteristic curve at the beginning stage of firing. That is, the arc voltage decreased automatically with increasing time (nozzle temperature) at a fixed arc current, and hence the input power decreased with increasing time at this stage. The input power decreased from 250 to $230 \mathrm{~W}$ in this time period. The produced thrust remained unchanged at about $130 \mathrm{mN}$, thus the thrust efficiency increased from $28.2 \%$ to $30.6 \%$ due to the decreased input power in this duration.

Previous results on $\mathrm{H}_{2} / \mathrm{N}_{2}$ gas mixture using a generator with a radiation-cooled nozzle [23] and with a regeneratively cooled nozzle [26] indicated that a high nozzle temperature of over $1300 \mathrm{~K}$ could have an unfavourable effect on the efficiency of flow energy conversion from a high enthalpy to an increased kinetic energy state.

The above results suggest that the anode/nozzle temperature, on the one hand, affects the arc volt-ampere characteristics, i.e. affects the electric power input and hence the gas heating, and on the other hand affects the process of energy conversion from high enthalpy to increased flow speed. When argon was used as the working gas, the input electric power was not increased to an appreciably high value and the stable nozzle temperature was much lower than the case using nitrogen or hydrogen or their mixture as the working gas. Thus, the nozzle temperature could mainly affect the volt-ampere characteristics of argon arcing and electric power input, especially in the case fired in the generator with a regeneratively cooled nozzle of very low bulk temperature.

The radiation loss by the emission of nozzle surface as shown in figure 8 with the measured temperature shown in 


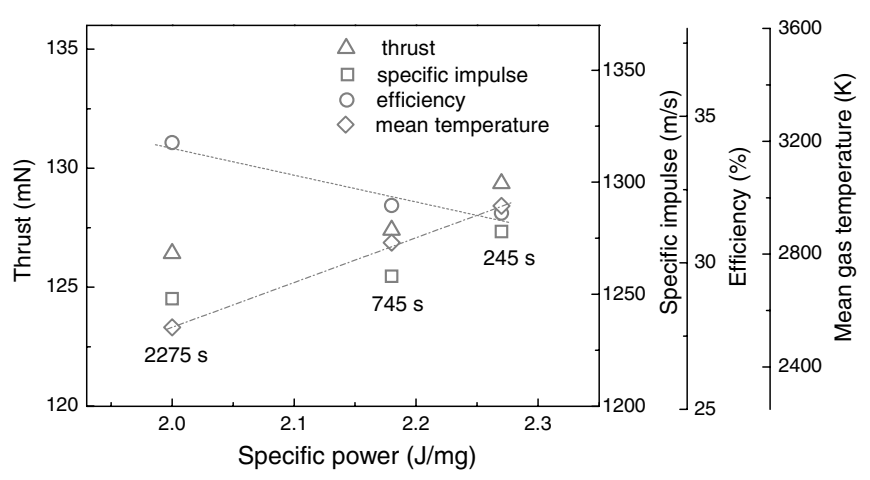

Figure 15. Variation of thrust, specific impulse, thrust efficiency and estimated mean exhaust temperature from the nozzle exit with specific power at a fixed argon flow rate of $100 \mathrm{mg} \mathrm{s}^{-1}$ and arc current of $8 \mathrm{~A}$.

figure 7 could be very low. The thrust efficiency is the ratio of the kinetic energy in the exhaust to the initial gas enthalpy which is nearly equal to the input electric power. Assuming the gas enthalpy exhausted from the nozzle exit equals the input power minus the kinetic energy, by omitting all the other losses such as radiation, heat conduction and frozen flow losses, figure 15 indicates the variations of the measured thrust and estimated specific impulse, thrust efficiency and mean exhaust gas temperature [27] with the specific power. The experimental conditions shown in figure 15 are the same as in figure 6. Working with exactly the same argon flow rate and arc current of $8 \mathrm{~A}$, the different specific power in figure 15 originated only from the different arc voltage affected by the anode/nozzle temperature (firing time), as shown in figure 6. The estimated average plume temperature and specific impulse (corresponding to the average axial velocity) decreased from $2960 \mathrm{~K}$ to $2530 \mathrm{~K}$ and from $1300 \mathrm{~m} \mathrm{~s}^{-1}$ to $1270 \mathrm{~m} \mathrm{~s}^{-1}$, respectively, at firing times $245 \mathrm{~s}$ and $2275 \mathrm{~s}$. The choice of unit for specific impulse $\left(\mathrm{m} \mathrm{s}^{-1}=\mathrm{N} \mathrm{s} \mathrm{kg}^{-1}\right)$ is to show more clearly its relationship to the effective kinetic energy in the exhaust plume.

It is seen that anode/nozzle temperature does have nonnegligible effects on the characteristics and performance of the plasma generator. Accordingly, one should take into consideration variations of the arc characteristics and plasma plume properties in the application process either for material heating and/or deposition, or for electric propulsion, when the plasma generator with a hot anode is used, especially during the period of rising anode/nozzle temperature at the beginning stage of firing.

\section{Conclusions}

Experimental results indicate that in the tested plasma generators with a hot anode/nozzle, the arc voltage rises with the increase in arc current at the beginning stage of firing, and then turns to falling characteristics with increasing arc current after the anode temperature has risen to certain elevated levels, irrespective of the radiation or regenerative anode cooling method, but the slow rising of the anode temperature delays the characteristics' transition in the case of regenerative cooling. The change in gas flow rate does not essentially affect the variation of the slopes of the volt-ampere characteristic curve with the anode temperature. The arc voltage increases with increasing gas flow rate and decreases with increasing arc current linearly, after a firing time of $1000 \mathrm{~s}$ for argon and $130 \mathrm{~s}$ for nitrogen or hydrogen using a generator with a regeneratively cooled nozzle. However, the variation of the hydrogen arc current affects its arc voltage only slightly. The anode/nozzle temperature could affect the arc volt-ampere characteristics, the gas heating and the energy conversion processes from high enthalpy to increased flow speed. The average plume temperature and axial velocity of the argon plasma decreased continuously with increasing anode temperature under a fixed set of working conditions of gas flow rate and arc current. Considering these findings, it may be necessary to consider the variation of arc characteristics and plasma plume properties in the application processes when a plasma generator with a hot anode is used, especially during the period of rising anode/nozzle temperature at the beginning stage of firing.

\section{Acknowledgments}

This work is supported by the National Natural Science Foundation of China under Grant Nos 50836007, 10775164 and 10921062 .

\section{References}

[1] Fauchais P, Montavon G, Vardelle M and Cedelle J 2006 Surf Coat. Technol. 2011908

[2] Fauchais P 2004 J. Phys. D: Appl. Phys. 37 R86

[3] Pan W X, Li G, Meng X, Ma W and Wu C K 2005 Pure Appl. Chem. 77373

[4] Pan W X, Meng X, Li G, Fei Q X and Wu C K 2005 Surf. Coat. Technol. 197345

[5] Beaber A R, Qi L J, Hafiz J, McMurry P H, Heberlein J V R, Gerberich W W and Girshick S L 2007 Surf. Coat. Technol. 202871

[6] Chen J H, Lu G H, Zhu L Y and Flagan R C 2007 J. Nanopart. Res. 9202

[7] Tymiak N, Gerberich W W, Blum J, Neuman A, Rao N P, McMurry P H, Heberlein J V R and Girshick S L 2001 J. Thermal Spray Technol. 10173

[8] Bottin B, Carbonaro M, Chazot O, Degrez G, Abeele D V, Barbante P, Paris S, Van Der Haegen V, Magin T and Playez M 2004 Contrib. Plasma Phys. 44472

[9] Xia W D, Li L C, Zhao Y H, Ma Q, Du B H, Chen Q and Cheng L 2006 Appl. Phys. Lett. 88211501

[10] Fonzo F D et al 2000 Appl. Phys. Lett. 77910

[11] Hafiz J et al 2004 Surf. Coat. Technol. 188-189 364

[12] Wilson F C 2006 Proc. 24th AIAA Int. Communications Satellite Systems Conf. (San Diego, CA) AIAA-2006-5306

[13] Butler G W and Cassady R J 1996 J. Propulsion Power 121026

[14] Curran F M, Nakanishi S 1986 Proc. 22nd AIAA/ASME/SAE/ASEE Joint Propulsion Conf. (Huntsville, $T X)$ AIAA-86-1505

[15] Yoshikawa T, Onoe K, Oba T, Yoshida H, Suzuki H and Morimoto S 1987 Proc. 19th AIAA/DGLR/JSASS Int. Electric Propulsion Conf. (Colorado Springs, CO) AIAA-87-1058

[16] Glogowski M J, Glocker B and Kurtz H L 1990 Proc. 21st AIAA/DGLR/JSASS Int. Electric Propulsion Conf. (Orlando, FL) AIAA-90-2575 
[17] Hoskins W A, Butler G W and Kull A E 1994 Proc. 30th AIAA/ASME/SAE/ASEE Joint Propulsion Conf. (Indianapolis, IN) AIAA-94-3124

[18] Curran F M and Haag T W 1992 J. Spacecraft Rockets 29444

[19] Yamada T, Shimizu Y, Toki K and Kuriki K 1992 J. Propulsion Power 8650

[20] Curran F M, Manzella D H and Pencil Eric J 1990 Proc. 21st Int. Electric Propulsion Conf. (Orlando, FL) AIAA-90-2582/NASA 103227

[21] Kuninaka H, Ishii M and Kuriki K 1986 J. Propulsion 2408
[22] Huang H J, Pan W X, Meng X and Wu C K 2009Proc. 19th Int. Symp. on Plasma Chemistry (Bochum, Germany) P3.12.07-459

[23] Pan W X, Li T and Wu C K 2009 Chin. Phys. Lett. 26125201

[24] Wu C K, Wang H X, Meng X, Chen X and Pan W X 2011 Acta Mech. Sin. 27152

[25] Wang H X, Chen X, Pan W X, Murphy A B, Geng J Y and Jia S X 2010 Plasma Sci. Technol. 12692

[26] Pan W X, Huang H J and Wu C K 2010 Plasma Sci. Technol. 12473

[27] Murphy A B and Arundell C J 1994 Plasma Chem. Plasma Process. 14451 